\title{
Science of hydraulic fracturing contains materials questions
}

\author{
By Melissae Fellet \\ Feature Editors Michael Marder and Tad Patzek
}

$\mathrm{H}$ orizontal drilling and hydraulic fracturing is becoming common across the United States as a method of producing oil and natural gas trapped in deep shale formations. Proponents argue that the process, commonly called "fracking," will spur economic growth by providing low-cost energy from a domestic source of natural gas. Opponents worry that leaks of gas and chemicals used during hydraulic fracturing could contaminate groundwater and impact public health.

A 2012 report on hydraulic fracturing prepared by the Pacific Institute, a non-profit research group, found little peer-reviewed literature on the process or its environmental impacts; thus, opinion dominates dialogue on the issue. The expertise of materials research, if turned to questions around hydraulic fracturing, could help bring more science-based information to the debate.

Conventional wells tap into pockets of oil and natural gas formed when the hydrocarbons collect in underground reservoirs. Well operators produce the hydrocarbons by drilling vertically into these reservoirs.

Unconventional wells access hydrocarbons where they originally formed inside shale formations. Hydraulic fracturing involves injecting a high-pressure fluid into the shale to generate a network of cracks through which gas and oil can flow. This process, when combined with horizontal drilling to increase access to the hydrocarbons, became economically viable for horizontal wells in shales only in the early 2000s.

The technological advances in unconventional drilling are fueling natural gas production in the United States. In 2011, shale gas accounted for $34 \%$ of US natural gas production. By 2040, shale gas is expected to be $50 \%$ of the country's total gas production.

Here's how the process of horizontal drilling and hydraulic fracturing works today. Well operators drill a hole vertically into the ground. Drilling continues at an angle as the bore nears the shale, often more than 2000 meters deep. Then the bore turns so the well runs horizontally through the shale layer.

Throughout drilling, the crew lines the bore with steel casings. After the well is fully drilled and lined, the crew blasts holes through the casing in the horizontal portion of the bore. Fluid is pumped into the well at high pressure, blasting out of the holes in each "fracturing stage" and cracking the rock sur- rounding the bore. There can be 10 to 20 fracturing stages along each horizontal section of a well, which extends for 1500-3000 meters. The "frac" fluid mostly consists of water, a suspended granular solid-like sand, and a pinch of chemicals that alter the viscosity of the fluid, prevent bacterial growth, and reduce corrosion. As much as 10,000 tons of sand fills the fractures and keeps the cracks open so that oil and gas can flow out of the rock and into the well.

In deep wells, the cracks can generate pressures approximating those at the bottom of the Pacific Ocean as they try to close. That force can crush silica sand, so other materials are under investigation as proppants. A granular form of bauxite resists crushing, but its use in hydrofracturing means gas wells and aluminum production compete for raw materials. Waste from mining, coal combustion, and glass recycling are also potential sources for stronger proppants.

The amount of hydrocarbons produced from an unconventional well depends on the breadth and extent of the crack network generated during hydraulic fracturing. Typically, this network has been explored by geophysicists and petroleum engineers; yet other scientific fields, like materials science, have knowledge relevant to the issue. Theories in the field of fracture dynamics describe how cracks spread through any material, with literature stretching back to the 1950s and 1960s. More work, however, is needed to adapt this information to questions involving hydraulic fracturing.

Some information about the spread of cracks in shale could come from understanding fracturing of brittle materials like glass, as shale is naturally brittle.

Specialists in fracture mechanics often seek to inhibit the spread of cracks, as practical applications of the field aim to ensure material integrity for construction or manufacturing. But in hydraulic fracturing, well operators want the fluid-generated fractures to spawn more cracks, creating a branched network that increases the volume of accessible hydrocarbon. Research on crack generation from an outward pressure of fluid has decades of history, but much of that work describes how cracks spread through one plane. Few studies investigate how cracks spread and branch into a threedimensional network like that created by hydraulic fracturing. 
Other factors that influence fracture formation are the pumping rate and pressure of the fluid. The viscosity of fluid influences energy dissipation and helps to keep the solid proppant, like sand, in suspension. The composition of the proppant also affects crack formation.

The best-studied models of fracture networks have a statistical character, where bonds between adjacent regions snap with a probability given by stresses in the local environment. These models can address important questions such as the way that failure stresses depend upon sample size. In recent experiments, Maya Kobchenko, at the University of Oslo, and her colleagues created a fracture network in a gel by infusing it with increasing amounts of carbon dioxide generated by yeast. Examination of the evolution of the network enabled the researchers to deduce simple explanations for the characteristic length and spacing of fractures ultimately created in the gel. The model systems, experimental and theoretical, utilized to study statistical fracture networks are extremely suggestive, but there is not yet a path from their findings to specific actions that could improve the transport properties of fractures in shales.

Even at the smallest scales, transport of gas within shales presents interesting materials problems. Paulo Monteiro, at the University of California, Berkeley, and his colleagues showed that in nanoporous materials such as shales, pressure dependence of permeability upon pressure can lead to transport processes obeying unexpected power laws. There are many concepts that impinge upon storage and motion of gas: adsorption, diffusion, porosity, fine-scale fractures. At a microscopic level, can they really be distinguished?

Another challenge for understanding fracture networks involves understanding how natural crack networks interact with networks generated by hydraulic fracturing. Interconnected networks of mineral veins or other hydrofractures can develop even in comparatively homogeneous rocks, such as thick mudstones in Southwest England.

Fracture growth and fluid flow behave similarly to invasion percolation processes, mathematical models of fluid movement through porous materials. However, existing fracture growth differs from closed/open percolation processes because it continues at points of high pressure and restricted fracture opening. Thus, modeling the dynamic interconnections between natural cracks and hydrofractures presents new scientific challenges.

Recent research shows how information from fluid mechanics and fracture dynamics can provide information about gas production from hydrofractured shale. Previous estimates assumed that production from horizontal and fractured wells was similar to that from conventional vertical wells. However, the well geometry and geologic differences between the two types of wells influence fluid flow, and thus production.

Tad Patzek, at The University of Texas at Austin, and his colleagues developed a model to estimate the amount of recoverable gas in horizontal wells, accounting for the basic physics and geometry of extraction. The researchers compared the model's description of the production trend to known production data from thousands of horizontal wells in Texas' Barnett

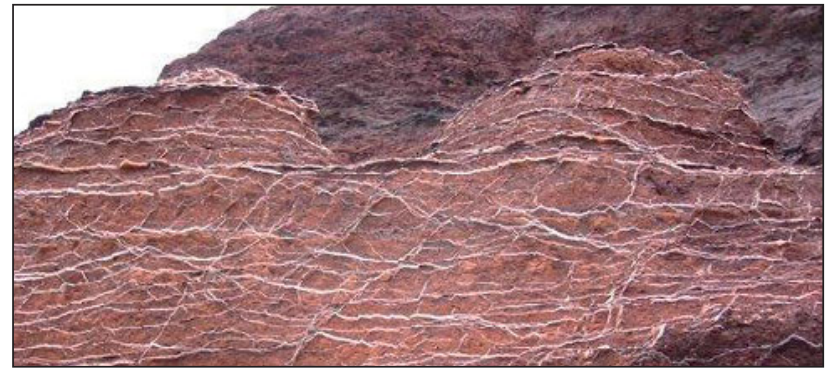

Veins of gypsum stretch through mudstone along the southwestern coast of England, creating a naturally occurring network of interconnected fractures. Understanding how natural fracture networks interact with those formed by fracking presents another challenge. Credit: Sonja Philipp. Reproduced from Frontiers in Earth Science (DOI: 10.3389/feart.2013.00004).

Shale. The estimates matched actual production for 2000 wells that showed interference, or evidence of a transitioning to an inevitable phase of exponential decline. Checking their estimates of the amount of gas coming from wells with an upper bound obtained by multiplying gas density into available volume, the researchers noticed that the gas actually being extracted is typically five times lower than the available amount; only $20 \%$ of gas is being recovered.

For 6,000 wells that were too young to show interference, the researchers set upper and lower bounds on production. Production rate is key to profitability. The impact of more accurate production estimates becomes clear when extended from this subset of wells in Texas to other shale formations. Small changes to predicted production rate could combine to create large effects on energy economics. Economic analyses that incorporate results of this model for other shales are underway, the researchers said.

Better imaging would also help provide more information about the fracture network, Patzek and his UT, Austin colleague Michael Marder said. Currently, some information about shale fractures comes from sensors detecting microseismic waves from imperceptible natural earthquakes. The resolution of this technique is too coarse to directly image many of the tiny cracks in a hydrofractured network. Another source of information is resistivity image logs. These are high-resolution plots of the electrical resistivity at the surface of the borehole. Particularly after comparison with core samples for calibration, they can be used to find pre-existing natural fractures intersecting a well. But this information is not sufficient to tease out the full three-dimensional structure of pre-existing flaws, let alone the network ultimately generated by the fracturing process.

Meanwhile, the debate about negative environmental effects from unconventional drilling continues. Despite occurrences of contaminated wells near unconventional drilling sites, regulators have not reported a connection between groundwater contamination and hydraulic fracturing of shale. Nevertheless, state legislatures are beginning to regulate unconventional drilling, and the US Congress discussed options for federal legislation in 2013.

Applying fracture mechanics to questions around hydraulic fracturing will not necessarily settle the debate on unconventional drilling. However, such studies contribute valuable scientific information to the debate, Marder said. 